\title{
Medicare: Ready for a perfect storm of reform?
}

A s Canada's new Conservative government settles into the more comfortable seats on the other side of the House, it will begin to adjust the levers of political and policy change. There will be necessary changes of personnel at senior bureaucratic levels, especially in key ministries such as health. Organizations with vested interests will regroup - some enjoying more access to government, others less.

Like others before them, this new government will view as obligatory the need to tinker with our health care system, the single largest public project in the country. And voters will not soon forget, from the Liberal era, the savaging of federal health transfer payments in the interest of salvaging a sputtering economy, or the subsequent series of health forums, commissions, lofty promises and increasingly desperate cash injections mustered in escalating attempts to repair the damage. Increasingly, pressure to not merely rehabilitate the system but fundamentally change it is coming from all directions; there are signs on the near horizon of a perfect storm of reform.

First, the new government is by nature more open than its predecessor to private enterprise and is more likely to draw consultants and advisers from the private sector. Second, two provinces in particular are either obliged to introduce private insurance for publicly funded services (Quebec) or have long had a hankering to do so (Alberta). In 2005 the Supreme Court ruled that, because the universal health care system in Quebec (and, by extension, in Canada) is a monopoly, the province is obliged to provide services in a timely manner, or else to allow individuals to purchase them outside of that monopoly as a matter of basic rights. Quebec has already launched background studies on the private health insurance option and is required to have these in place by the Supreme Court's deadline later this year. A subtext to these developments is Quebec's strong tradition of support for private enterprise, a fact that may have been demonstrated in the last election with the drop in popular support for the hard-left policies of the Bloc toward the soft-right policies of the Conservatives (minus the evangelical part). (Quebec's current pre- mier, we should remember, was once the federal leader of the former Progressive Conservative party.) Somewhat paradoxically, oil-rich Alberta, unburdened by provincial debt and the only province able to afford platinum public health care, has long advocated a publicly financed parallel private system.

A third portent of reform is the Canadian Wait Times Alliance, whose members include the CMA and 6 physician subspecialty societies. The Alliance has been focusing attention on highly visible components of care - cancer treatment, cardiac procedures, diagnostic imaging, joint replacements and cataract surgery, to the satisfaction of anxious patients everywhere. However, this initiative may be less useful than it seems. The new wait-time benchmarks are no better than the norm in some regions, and there is little hard evidence that waiting for elective surgery adds significantly to the burden of illness or that a few weeks' delay in starting cancer therapy will have appreciable effect on survival. (The effect on patient satisfaction is another matter.)

We predict that the new Canadian government will attempt a highly visible and inevitably expensive pursuit of a "Patient Wait Time Guarantee," finding a willing partner in Alberta and a desperate one in Quebec. Indeed, given the political momentum that health care reform has gathered in the last few years, the new government may only have to sit back and watch these developments happen.

But there is a lot more to the health-reform story. If we are to invest more, collectively or privately, in health care, let our urgency be directed not toward late-stage or heroic measures so much as toward the early stages of illness and of life. Speeding up the conveyor belt of standardized interventions is well and good, but the emphasis of reform should be on primary care - on providing better preventive care services and advice, on encouraging patients to lose weight, exercise, and take appropriate medications when necessary for hypertension, diabetes and other chronic diseases, on providing integrated, patient-centred care during end-stage disease, and on providing a better quality of life for geriatric patients which, granted, might also mean getting that cataract surgery done sooner. - CMAJ 